\title{
Cerebral distribution of cardiac output in newborn infants
}

\author{
T Kusaka, K Okubo, K Nagano, K Isobe, S Itoh
}

Arch Dis Child Fetal Neonatal Ed 2005;90:F77-F78. doi: 10.1136/adc.2004.058487

Cerebral blood flow and output of the left ventricle were simultaneously investigated in 17 infants using multichannel near infrared spectroscopy and pulse dye densitometry with indocyanine green. Cardiac output and cerebral blood flow were positively related. The control of cardiac output is important in the regulation of cerebral blood flow in infants.

7 he major regulatory mechanisms for cerebral blood flow $(\mathrm{CBF})$ in infants are autoregulation, arteriolar $\mathrm{CO}_{2}, \mathrm{O}_{2}$ delivery, blood glucose, and neural activity. It has also been shown that the cardiovascular system regulates CBF through variation in cardiac output (CO) and distribution of blood flow.

A new method of calculating CBF using indocyanine green (ICG) as a tracer with near infrared spectroscopy (NIRS) has been developed. ${ }^{12}$ We previously reported that multichannel NIRS (MNIRS) and pulse dye densitometry (PDD) using ICG can be used to measure regional CBF distribution in infants. ${ }^{2}$ PDD uses the general principles of pulse oximetry to measure the concentration ratios of ICG and haemoglobin $(\mathrm{Hb})$ in arterial blood. Therefore ICG concentration in arterial blood can be estimated without collecting blood if $\mathrm{Hb}$ concentrations are obtained in a clinical setting. ${ }^{3}$

In this study, measurement of CBF using MNIRS and PDD and measurement of CO using PDD with ICG were carried out simultaneously in 17 infants, and the relation between $\mathrm{CO}$ and $\mathrm{CBF}$ was investigated.

\section{SUBJECTS AND METHODS}

Measurements were carried out in 19 infants undergoing neonatal intensive care at the Maternal Perinatal Center of Kagawa University Hospital. Written informed consent was obtained from the parents of each infant. The study was also approved by a local ethics committee. Data from two infants were excluded from the analysis because the measurements were affected by movement artefacts. Successful measurements were obtained in 17 infants (mean (SD) gestational age 32.9 (4.3) weeks (range 24.1-38.1) and birth weight 1588 (686) g (range 65l-3200)). Median age at the time of measurement was 5 days (range 0-82).

A bolus of ICG $(0.2 \mathrm{mg} / \mathrm{kg})$ was injected into the peripheral vein of each infant. Eight light incident and eight detector fibres were placed on the right or left parietotemporal region of the head, each with an interoptode distance of $2 \mathrm{~cm}$, and 24 measuring positions were defined. Changes in cerebral ICG concentration in a $6 \mathrm{~cm} \times 6 \mathrm{~cm}$ field were recorded using MNIRS (Optical Encephalography System; Hitachi Medical Co Ltd, Chiba, Japan). Data were collected every 0.1 second after the appearance of dye in the optical field. The accumulation of cerebral ICG at a specific time later $(\mathrm{Q}(\mathrm{t}))$ was calculated. Simultaneously, PDD (DDG-2001; Nihon-Koden Co, Tokyo, Japan) was used to measure the arterial blood concentration of ICG $(\mathrm{Pa})$. The optical probe was attached to the right or left wrist. CBF was calculated from the Fick equation modified for zero venous concentration during the first six seconds after the appearance of dye in each optical field. With the use of measured cerebral ICG $(\mathrm{mg} / \mathrm{l} / \mathrm{cm})$, arterial ICG $(\mathrm{mg} / \mathrm{l})$, measured interoptode distance $(\mathrm{cm})$, and differential path length factor for infants (4.39), where $\mathrm{K}$ is a constant reflecting the cerebral tissue density (1.05), and correcting to $100 \mathrm{~g}$ tissue mass, CBF can be obtained as follows:

$$
\mathrm{CBF}(\mathrm{ml} / \mathrm{l} 00 \mathrm{~g} / \mathrm{min})=\mathrm{K} \times \mathrm{Q}(\mathrm{t}) /{ }_{0}^{\mathrm{t}} \mathrm{Padt}
$$

CBF was defined as the mean from 24 channels.

Left ventricle $\mathrm{CO}$ was calculated as follows from the first dilution curve on a PDD:

$$
\mathrm{CO}(\mathrm{l} / \mathrm{min})=\mathrm{D}(\mathrm{mg}) / \mathrm{G}(\mathrm{mg} / \mathrm{min} / \mathrm{l})
$$

where D is the amount of ICG administered, and G is the area under the first dilution curve obtained by extrapolation of the first decay slope to infinity.

\section{RESULTS}

Table 1 shows the values for left ventricle $\mathrm{CO}$ and $\mathrm{CBF}$. CO and $\mathrm{CBF}$ in the parietotemporal region were 202.8 (90.6) $\mathrm{ml} /$ $\mathrm{kg} / \mathrm{min}$ and $15.3(4.2) \mathrm{ml} / 100 \mathrm{~g} / \mathrm{min}$ respectively. A significant positive relation was found between $\mathrm{CO}$ and $\mathrm{CBF}$ : $\mathrm{CBF}$ $=0.03 \mathrm{CO}+8.71(r=0.70, \mathrm{p}=0.002)($ fig 1$)$. The relation between $\mathrm{CBF}$ and mean arterial blood pressure or between $\mathrm{CBF}$ and $\mathrm{PvCO}_{2}$ was not significant. However, $\mathrm{CBF}$ and blood $\mathrm{Hb}$ showed a significant positive relation $(r=0.49, \mathrm{p}=$ $0.045)$.

\section{DISCUSSION}

This is the first report of a significant positive relation between $\mathrm{CO}$ and CBF in infants. The results of this study show that CO is a major factor affecting CBF. From our data,

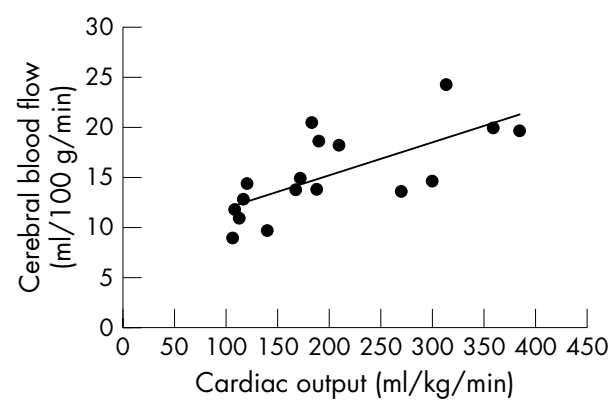

Figure 1 Correlation between cardiac output and cerebral blood flow measured by multichannel near infrared spectroscopy and pulse dye densitometry using indocyanine green. The linear regression line is described by $\mathrm{CBF}=0.03 \mathrm{CO}+8.71$, with a correlation coefficient of 0.70 and $p=0.002$.

Abbreviations: $\mathrm{CBF}$, cerebral blood flow; $\mathrm{CO}$, cardiac output; $\mathrm{Hb}$, haemoglobin; ICG, indocyanine green; MNIRS, multichannel NIRS; NIRS, near infrared spectroscopy; PDD, pulse dye densitometry 
Table 1 Cardiac output and cerebral blood flow in 17 infants

\begin{tabular}{|c|c|c|c|c|c|c|c|c|}
\hline Infant & $\begin{array}{l}\text { Gestational } \\
\text { age (weeks) }\end{array}$ & $\begin{array}{l}\text { Birth } \\
\text { weight (g) }\end{array}$ & $\begin{array}{l}\text { Postnatal } \\
\text { age (days) }\end{array}$ & $\begin{array}{l}\text { MABP } \\
\text { (torr) }\end{array}$ & $\begin{array}{l}\text { Blood } \mathrm{Hb} \\
\text { (g/l) }\end{array}$ & $\begin{array}{l}\mathrm{PvCO}_{2} \\
\text { (torr) }\end{array}$ & $\begin{array}{l}\text { Cardiac output } \\
(\mathrm{ml} / \mathrm{min} / \mathrm{kg})\end{array}$ & $\begin{array}{l}\text { Cerebral blood flow } \\
(\mathrm{ml} / \mathrm{min} / 100 \mathrm{~g})\end{array}$ \\
\hline 1 & 24.1 & 740 & 49 & 44 & 106 & 37.0 & 300 & 14.6 \\
\hline 2 & 24.4 & 651 & 79 & 67 & 105 & 33.0 & 270 & 13.7 \\
\hline 3 & 28.3 & 1064 & 13 & 46 & 129 & 41.0 & 385 & 19.7 \\
\hline 4 & 31.1 & 961 & 4 & 35 & 130 & 36.4 & 314 & 24.3 \\
\hline 5 & 31.4 & 1061 & 8 & 67 & 190 & 38.0 & 210 & 18.2 \\
\hline 6 & 31.4 & 1290 & 7 & 31 & 113 & 34.0 & 188 & 13.9 \\
\hline 7 & 32.3 & 1463 & 3 & 43 & 161 & 34.0 & 140 & 9.7 \\
\hline 8 & 32.4 & 1426 & 5 & 51 & 140 & 44.5 & 168 & 13.9 \\
\hline 9 & 33.6 & 1852 & 4 & 52 & 139 & 38.0 & 172 & 14.9 \\
\hline 10 & 33.6 & 1634 & 4 & 57 & 170 & 34.4 & 184 & 20.5 \\
\hline 11 & 33.7 & 1876 & 19 & 61 & 160 & 44.0 & 190 & 18.6 \\
\hline 12 & 36.7 & 2261 & 0 & 67 & 149 & 41.8 & 121 & 14.4 \\
\hline 13 & 36.7 & 2355 & 0 & 38 & 140 & 45.7 & 109 & 11.8 \\
\hline 14 & 36.7 & 2398 & 0 & 40 & 130 & 46.7 & 117 & 12.8 \\
\hline 15 & 37.4 & 3200 & 29 & 77 & 108 & 41.6 & 113 & 11.0 \\
\hline 16 & 37.7 & 1790 & 5 & 42 & 185 & 42.9 & 360 & 19.9 \\
\hline 17 & 38.1 & 980 & 81 & 58 & 72 & 40.0 & 107 & 9.0 \\
\hline Mean & 32.9 & 1588 & 18 & 52 & 140 & 39.6 & 202.8 & 15.3 \\
\hline SD & 4.3 & 686 & 26 & 13 & 30 & 4.4 & 90.6 & 4.2 \\
\hline
\end{tabular}

the blood flow distribution to the brain of left ventricular output is estimated to be $8-11 \%$ if the brain is assumed to weigh $10-15 \%$ of body weight. ${ }^{5}$ This value is higher than the combined CO reported for the fetus of a lamb (3\%). ${ }^{6}$ This is because cerebral $\mathrm{O}_{2}$ consumption and metabolic rate in infants are higher than in the fetus of a lamb.

Measurements of CO and CBF using MNIRS and PDD are simple and fast, and repeated measurements in an infant at the bedside are possible. There is no irradiation and no need for blood collection, and measurements can be made with little stress to the patient. However, further studies are needed in infants, especially for evaluation of the sensitivity and reliability of $\mathrm{CO}$ and CBF measurements using MNIRS and PDD, before the method can be applied to a clinical setting.

In conclusion, we found this procedure both feasible and very useful for the elucidation of $\mathrm{CO}$ and $\mathrm{CBF}$ disturbance during the acute phase of illness in infants.

\section{Authors' affiliations}

T Kusaka, K Okubo, K Nagano, K Isobe, S Itoh, Kagawa University, Kagawa, Japan
Competing interests: none declared

Correspondence to: Dr Kusaka, Maternal Perinatal Center and Faculty of Medicine, Kagawa University, 1750-1 Mikicho, Kitagun, Kagawa 761-0793, Japan; kusaka@kms.ac.jp

Accepted 2 August 2004

\section{REFERENCES}

1 Roberts I, Kirkham FJ, Lloyd-Thomas A, et al. Estimation of cerebral blood flow with near infrared spectroscopy and indocyanine green. Lancet 1993;342:1425.

2 Kusaka T, Isobe K, Nagano K, et al. Estimation of regional cerebral blood flow distribution in infants by near-infrared topography using indocyanine green. Neuroimage 2001;13:944-52.

3 lijima T, Aoyagi T, Iwao Y. Cardiac output and circulating blood volume analysis by pulse dye-densitometry. J Clin Monit 1997;13:81-9.

4 Nagano K, Kusaka T, Okubo K, et al. Estimation of circulating blood volume in infants using the pulse dye densitometry method. Paediatr Anaesth 2004;in press.

5 Larroche JC. Development of the central nervous system. In: Developmental pathophysiology of the neonate. Amsterdam: Excerpta Medica, 1977:319-53.

6 Jensen A, Roman C, Rudolph AM. Effects of reducing uterine blood flow on fetal blood flow distribution and oxygen delivery. J Dev Physiol $1991 ; 15: 309-23$ 